\title{
Hevostarhojen valumavesien puhdistaminen
}

\author{
Aaro Närvänen, Håkan Jansson ja Jaana Uusi-Kämppä \\ MTT (Maa- ja elintarviketalouden tutkimuskeskus), Kasvintuotannon tutkimus, E-talo, 31600 Jokioinen, \\ aaro.narvanen@mtt.fi
}

\section{Tiivistelmä}

Hevostarhojen valumavesistä on mitattu toisinaan jopa yhtä suuria fosforipitoisuuksia kuin haja-asutuksen puhdistamattomista jätevesistä. Tarhoista valumavesiin joutuvan fosforin määrä onkin hevosta kohden samaa suurusluokkaa kuin yhden asukkaan vuotuinen jätevesien fosforimäärä. Viime vuosina hevosten sekä niiden tarhojen määrä ovat kasvaneet. Siten tarhojen suunnitteluun ja rakentamiseen sekä valumavesien käsittelyyn tulee kiinnittää huomiota.

Ypäjän Hevosopistolla sijaitsevan B-pihaton tarhan (0,5 ha) yhteyteen rakennettiin syksyllä 2003 valumavesien käsittelyä varten ferrisulfaattiannostelu, laskeutusallas ja hiekkasuodin. Kemikaalin annostelu tapahtuu virtaavaan veteen liotussuppilosta. Muovikaivoon asennettuun annostelijaan mahtuu kerralla noin 20 kg Ferix-3:a. Rakeinen kemikaali liukenee veteen virtaaman mukaan (noin 1:10000). Kemikaalilla saostettu vesi johdetaan putkea (D110 mm) pitkin laskeutusaltaaseen $\left(100 \mathrm{~m}^{2}\right)$, jonka yhdessä luiskassa on hiekkasuodatin. Ensimmäisen seurantavuoden tulosten mukaan puhdistamo poisti valumaveden liuenneesta fosforista $95 \%$, kokonaisfosforista $82 \%$ ja kokonaistypestä $62 \%$. Myös ulosteesta peräisin olevien mikrobien tiheydet valumavedessä pienenivät puhdistamossa. Vuoden 2007 alusta lähtien tarha ei ole ollut talvikäytössä, mutta kuormitusseurantaa on edelleen jatkettu EquineLifehankkeen puitteissa.

Hevosopisto Oy:llä Ypäjällä vuonna 2007 alussa käyttöön otetun D-pihaton kolmen tarhan (1,2 ha) vedet käsitellään kemiallisen saostuksen ja laskeutusaltaan avulla. Puhdistamossa Ferix-3-kemikaali liukenee verkkosuppilosta ojaveteen v-padon yhteydessä. Vastaavanlainen annosteluautomaatti on toiminut lupaavasti myös peltovesien saostuksessa jopa $100 \mathrm{l} / \mathrm{s}$ virtaamiin asti.

Kuuman Hevoset/Alivio Oy:n islanninhevostallilla Jokioisilla testattiin hakkeen käyttöä hevostarhan pinnoitteena. Neljän tarhan alue (76 m x 50 m) salaojitettiin poikittaissuuntaisesti 9,5 metrin jaolla. Reunimmaisiin tarhoihin levitettiin $20 \mathrm{~cm}$ haketta saven päälle. Hakkeen sekaan sekoitettiin $160 \mathrm{~kg}$ rakennuskalkkia. Keskimmäisiin tarhoihin asennettiin suodatinkangas, jonka päälle levitettiin $10 \mathrm{~cm}: n$ kerros soraa ja soran päälle $10 \mathrm{~cm}: n$ kerros haketta, johon sekoitettiin $160 \mathrm{~kg}$ ferrisulfaattia (Ferix-3). Kussakin tarhassa on ollut keskimäärin 3-4 hevosta 11 tuntia vuorokaudessa ympäri vuoden. Eri käsittelyjen salaojavedet johdettiin omiin näytteenottokaivoihin, joista vesinäytteitä otettiin valumahuippujen aikana. Sekä liuenneen että kokonaisfosforin pitoisuudet ovat kahden seurantavuoden aikana olleet ferrisulfaatilla käsitellyn alueen salaojavesissä noin puolet rakennuskalkilla käsitellyltä alueelta tulleiden vesien pitoisuuksista.

Fosforin saostus ferrisulfaatilla on osoittautunut kustannustehokkaaksi menetelmäksi hevosten tarhavesien puhdistuksessa. Jatkossa on vielä selvitettävä tarhojen pintakerroksessa käytettävien kemikaalien sopivia annosmääriä niiden happamoittavan vaikutuksen vuoksi.

\section{Avainsanat}

ferrisulfaatti, fosforikuormitus, hevonen, jaloittelutarhat, vesien puhdistus, vesistökuormitus 


\section{Johdanto}

Viimeisten viiden vuoden aikana on hevosten määrä Suomessa lisääntynyt keskimäärin noin 1500 hevosella vuodessa (http://www.hippos.fi/hippos/tilastot/jalostus_ja_kasvatus/hevoskannan_kehitys.php). Tämä lisääntyminen on keskittynyt taajamien ympäristöön. On esitetty epäilyjä, että lisääntyvä hevosmäärä aiheuttaa ravinnekuormitusta ja siten myös lähistöllä olevien pintavesien laadun heikkenemistä. Hevostarhojen pintamaassa on paljon helppoliukoista fosforia. Sadetuskokeissa on havaittu korkeiden viljavuusfosforin pitoisuuksien heijastuvan korkeina valumaveden liuenneen fosforin pitoisuuksina (Närvänen ym. 2007). Jaloittelutarhojen päivittäisellä siivoamisella voidaan päästä fosforikuormituksessa murto-osaan siivoamattomaan verrattuna (Airaksinen ym. 2007). Fosforin lisäksi tarhavesissä myös ulosteesta peräisin olevien mikrobien tiheydet voivat olla suuria (Uusi-Kämppä ym. 2007ab, 2008).

Alustavissa hevosvesien saostuskokeissa saatiin hevostarhojen ja tallialueiden vesistä fosforipitoisuus alenemaan ferrisulfaattisaostuksen ja selkeytyksen avulla niin, että fosforia oli enää keskimäärin saman verran kuin metsien valumavesissä (Närvänen ym. 2001).

\section{Aineisto ja menetelmät \\ B-pihaton puhdistamo Ypäjällä}

Pihaton makuuhalli ja ulkoilualue ovat olleet kyseisessä käytössä vuodesta 1981 alkaen. Pihatossa pidetään nuoria hevosia talvikautena. Hevosten määrä alueella vaihtelee vuosittain ollen yleensä noin 10 (5-20). Hevoset ruokitaan ulkona. Korsirehuja varten on ruokintakaukalo, johon heinät laitetaan. Hevoset syövät sieltä vapaasti eli rehua on jatkuvasti tarjolla. Viime vuosina on ollut myös käytössä ruokintakärry, josta hevoset ovat saaneet heinänsä. Väkirehuja ja kivennäisiä varten on katoksellinen ruokintakaukalo. Makuuhallin oven edusta ja ruokintakaukaloiden lähistön pintamaa poistetaan ja samalla kyseisellä paikalla olevat hevosten jätökset siivotaan yleensä kerran vuodessa kesätauon aikana. Paikalle tuodaan uutta hiekkaa. Hevosten sontaa kerätään ajoittain myös ulkoilualueelta, mutta ei säännöllisesti.

Noin puolen hehtaarin kokoisen pihattotarhan valumavedet saostetaan ferrisulfaatilla ja johdetaan noin $100 \mathrm{~m}^{2}$ :n kokoisen lasketusaltaan ja hiekkasuodatuksen kautta avo-ojaan. Ferrisulfaatti (Ferix-3) annostellaan altaaseen tulevaan veteen salaojakaivon kautta. Salaojakaivossa olevasta annosteluputkesta vesivirtaus liuottaa kemikaalia pinnankorkeuden mukaisesti (Kuva 1). Annostelun karkea säätö toteutettiin pH:n seurannalla ja kemikaalin vuorokautisen kulutuksen perusteella.

Pihattotarhan valumavesien keräämiseksi yhteen pisteeseen tarhan itäreunaa korotettiin ja eteläreunalle kaivettiin oja, jonka alapäähän asennettiin sadevesikaivo näytteenottoa varten. Ojavesi johdetaan putkea pitkin kemikaalin annostelukaivon kautta $100 \mathrm{~m}^{2}:$ n kokoiseen ja metrin syvyiseen laskeutusaltaaseen, josta vesi poistuu hiekkasuodatuksen kautta salaojaan. Valumahuippujen aikana kaikki vesi ei ehdi kulkeutua suodattimen kautta. Tätä varten hiekkasuodattimen salaojaveden poistokaivon yläreunaan tehtiin ylivirtausaukko. Hiekan sisään laitettiin kahteen vakoon rakeista kalkkia yhteensä $80 \mathrm{~kg}$ tasoittamaan happaman saostuskemikaalin aiheuttamaa $\mathrm{pH}$-vaihtelua. Alue viimeisteltiin kylvämällä valkoapilan siementä ja nurmikonsiemenseosta altaan luiskiin ja kaivuumassojen levitysalueelle.

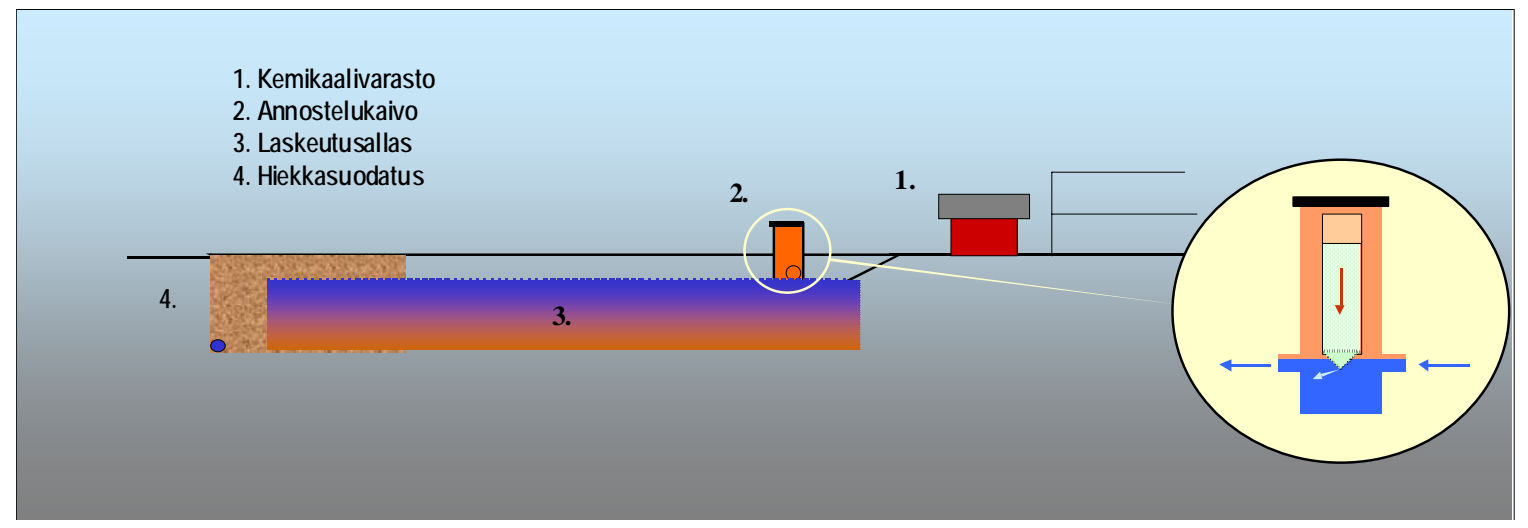

Kuva 1. B-pihaton tarhan valumavesien puhdistamon periaatepiirros. 


\section{D-pihaton puhdistamo}

Vuonna 2007 käyttöön otetun 16 hevosen pihaton valumavesille rakennettiin laskeutusallas ja kemiallinen saostus. Tilavuudeltaan 300 litran muovilaatikosta ferrisulfaatti (Ferix-3) valuu putkea (D $200 \mathrm{~mm}$ ) pitkin verkkosuppiloon, jonka silmäkoko on $4 \mathrm{~mm} \times 4 \mathrm{~mm}$ (Kuva 2). D-pihaton puhdistamon tekniikkaa on testattu ojaveden fosforin saostuksessa Jokioisten Rehtijärven valuma-alueella (Närvänen \& Jansson, 2007).

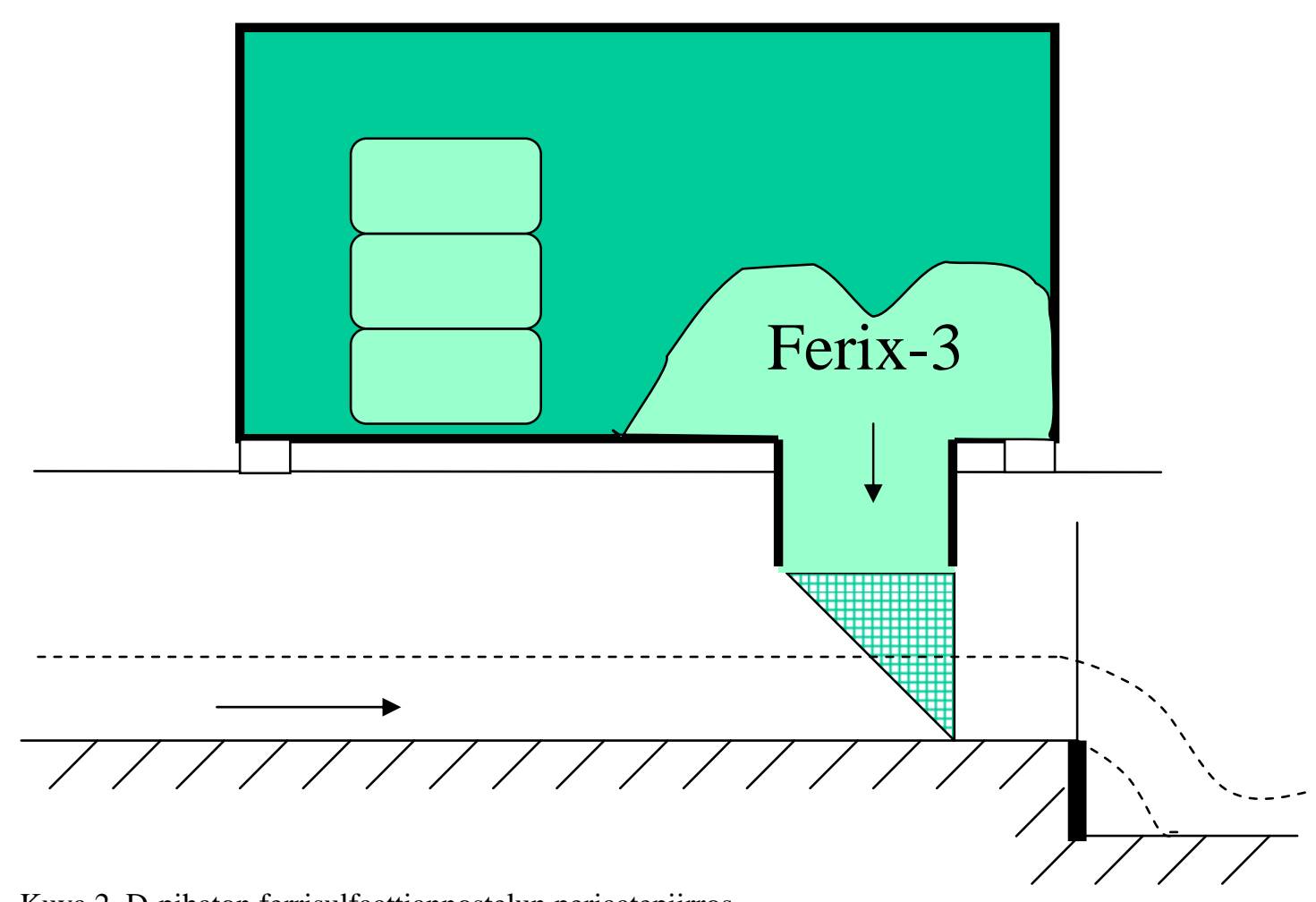

Kuva 2. D-pihaton ferrisulfaattiannostelun periaatepiirros.

\section{Kuuman haketarhat}

Jokioisten Kuuman tallilla kokeiltiin puuhaketta tarhan pohjassa. Kokeilussa verrattiin hakkeeseen sekoitetun rautasulfaatin ja rakennushienokalkin vaikutuksia. Kemikaalilisäyksellä pyrittiin hidastamaan hakkeen maatumista ja sitomaan liukoista fosforia. Kumpaakin kemikaalia levitettiin keskimäärin 84 g/m² (http://www.equinelife.fi/files/ympfoorumi2006/aaro_narvanen_valumavedet.pdf).

\section{Vesinäytteet}

Vesinäytteet otettiin puolen litran muovipulloihin. Puhdistamon vesinäytteet otettiin valumapainotteisesti siten, että pyrittiin ottamaan tulevasta ja lähtevästä vedestä valumahuipun aikana näytteitä. Joitakin näytteitä lähtevästä vedestä otettiin myös valumahuipun jälkeen, koska allas tasasi lähtevän veden valumia ja haluttiin nähdä, kuinka puhdistamo toimi yhden valumahuipun ajan. Kuuman haketarhojen salaojavesistä otettiin näytteitä valumahuippujen aikana. Vesinäytteet säilytettiin analysointipäivään saakka kylmävarastossa $\left(+2^{\circ} \mathrm{C}\right)$. Näytteistä märitettiin liuennut fosfori, kokonaisfosfori, ammonium-, nitraatti- ja kokonaistyppi, pH ja johtoluku. Kokonaisfosfori mitattiin happohajotuksen (fluorivety rikkihappo) jälkeen.

\section{Tulokset ja tulosten tarkastelu}

\section{B-pihaton puhdistamo}

Liuenneen fosforin poistuma puhdistamon koko toiminta-ajan on ollut pitoisuuksista laskettuna keskimäärin $84 \%$. Kokonaisfosforin poistuma on ollut $69 \%$ ja kokonaistypen poistuma $54 \%$. Kuvasta 3 ja 4 voidaan havaita, että poistuvan veden liuenneen fosforin pitoisuus on ollut kolmella 
näytteenottokerralla yli $1 \mathrm{mg} / \mathrm{l}$. Samanaikaisesti $\mathrm{pH}$ on ollut poistuvassa vedessä samalla tasolla kuin tulevassa vedessä. Tämä on johtunut kemikaalin loppumisesta annosteluputkessa. Koska annosteluputkeen mahtuu kemikaalia vain 12 kg, suurten virtaamien aikana pitäisi käydä lähes päivittäin tarkistamassa kemikaalin kulutusta. Alkuvaiheen aikana poistuvan veden korkea $\mathrm{pH}$ oli tulevan veden $\mathrm{pH}: n$ tasolla. Samanaikaisesti liuennutta fosforia poistui silti hyvin. Tämä selittyy hiekan sekaan lisätyn kalkin neutraloivalla vaikutuksella, joka kuitenkin jäi lyhytaikaiseksi (Kuvat 3 ja 4). Ferrisulfaattisaostus näytti myös hieman pienentävän ulostemikrobien tiheyksiä valumavedessä (Uusi-Kämppä ym. 2007a).

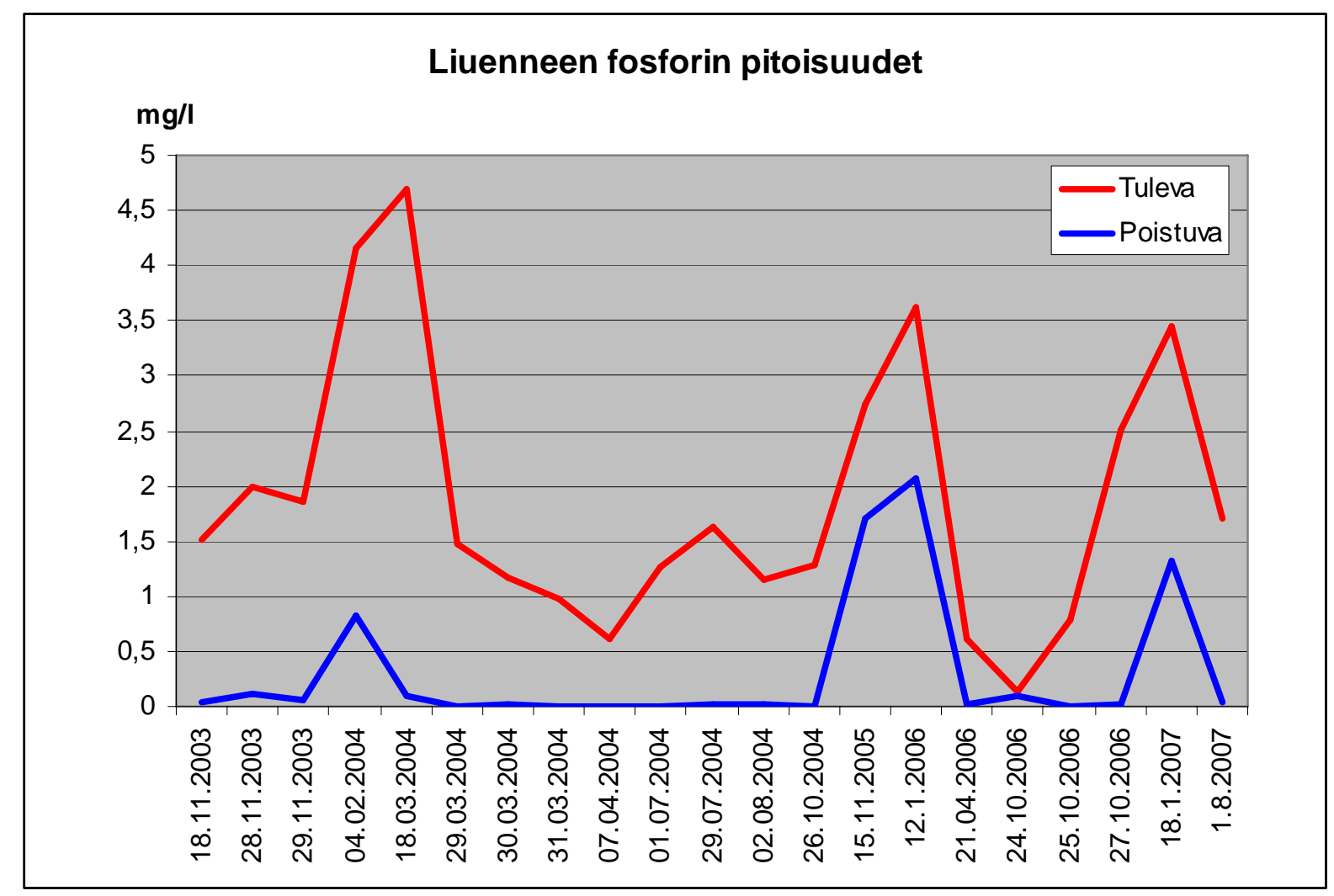

Kuva 3. Liuenneen fosforin pitoisuudet B-pihaton puhdistamon tulevassa ja poistuvassa vedessä. 


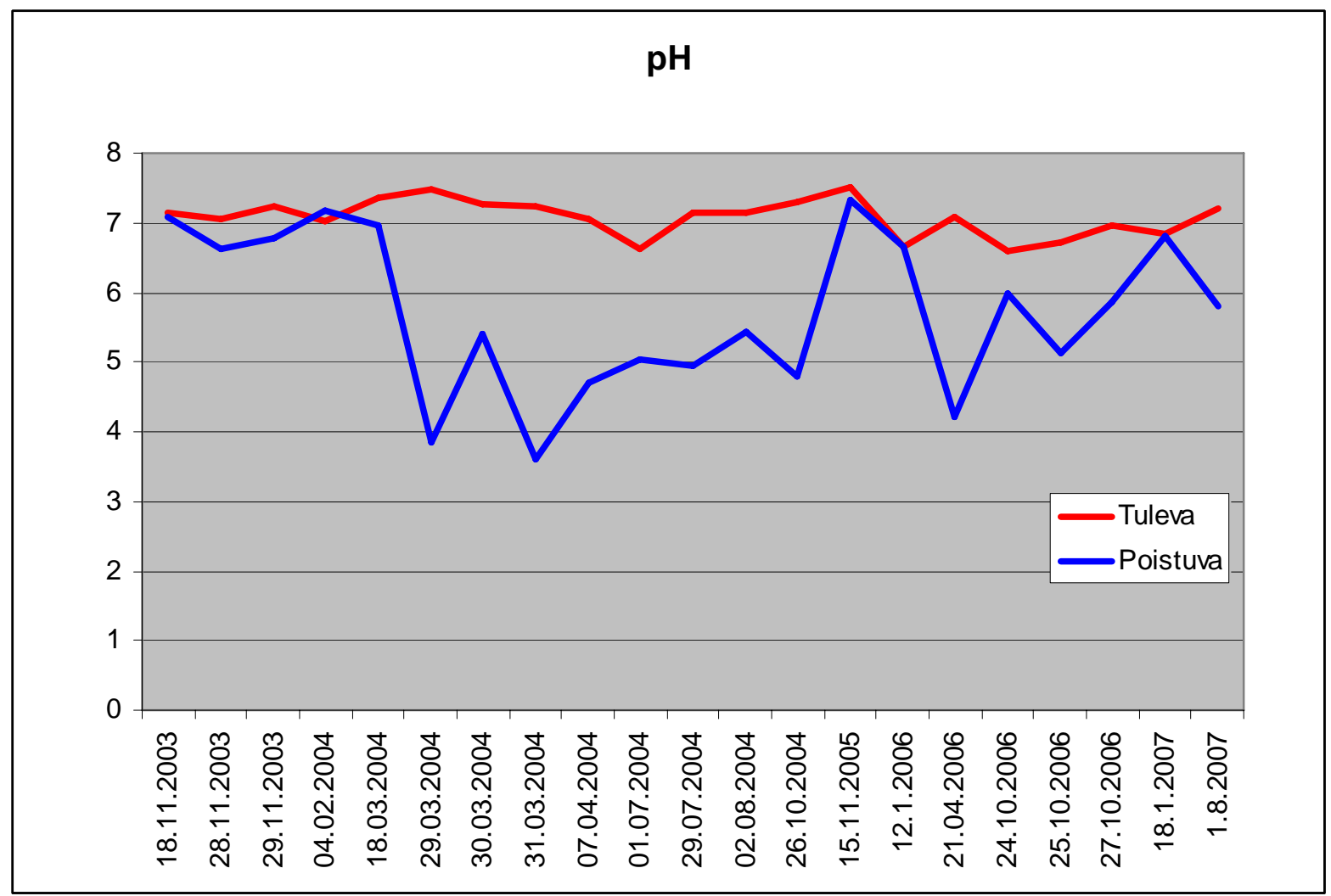

Kuva 4. B-pihaton puhdistamon tulevan ja poistuvan veden $\mathrm{pH}$.

\section{D-pihaton puhdistamo}

Liuenneen fosforin poistuma puhdistamon toiminnan alussa kesällä 2007 on ollut pitoisuuksista laskettuna keskimäärin 45 \%. Kokonaisfosforin poistuma oli 48 \% ja kokonaistypen poistuma 63 \% ja pH aleni 6,9:stä 4,6:een.

\section{Kuuman haketarhat}

Vuoden 2005 jälkeen Ferix-3:Ila käsiteltyjen haketarhojen salaojavesien liuenneen fosforin pitoisuudet olivat selvästi alemmalla tasolla (keskimäärin 61 \%) kuin rakennushienokalkilla käsiteltyjen haketarhojen salaojavesipitoisuudet. Vastaavasti kokonaisfosforipitoisuus oli myös selvästi alemmalla tasolla (55 \%), mutta kokonaistyppipitoisuus oli vain vähän alhaisempi (8 \%). Ferix-3:lla käsiteltyjen tarhojen salaojaveden pH oli keskimäärin 0,26 pH-yksikköä alempi (Kuvat 5 ja 6). 


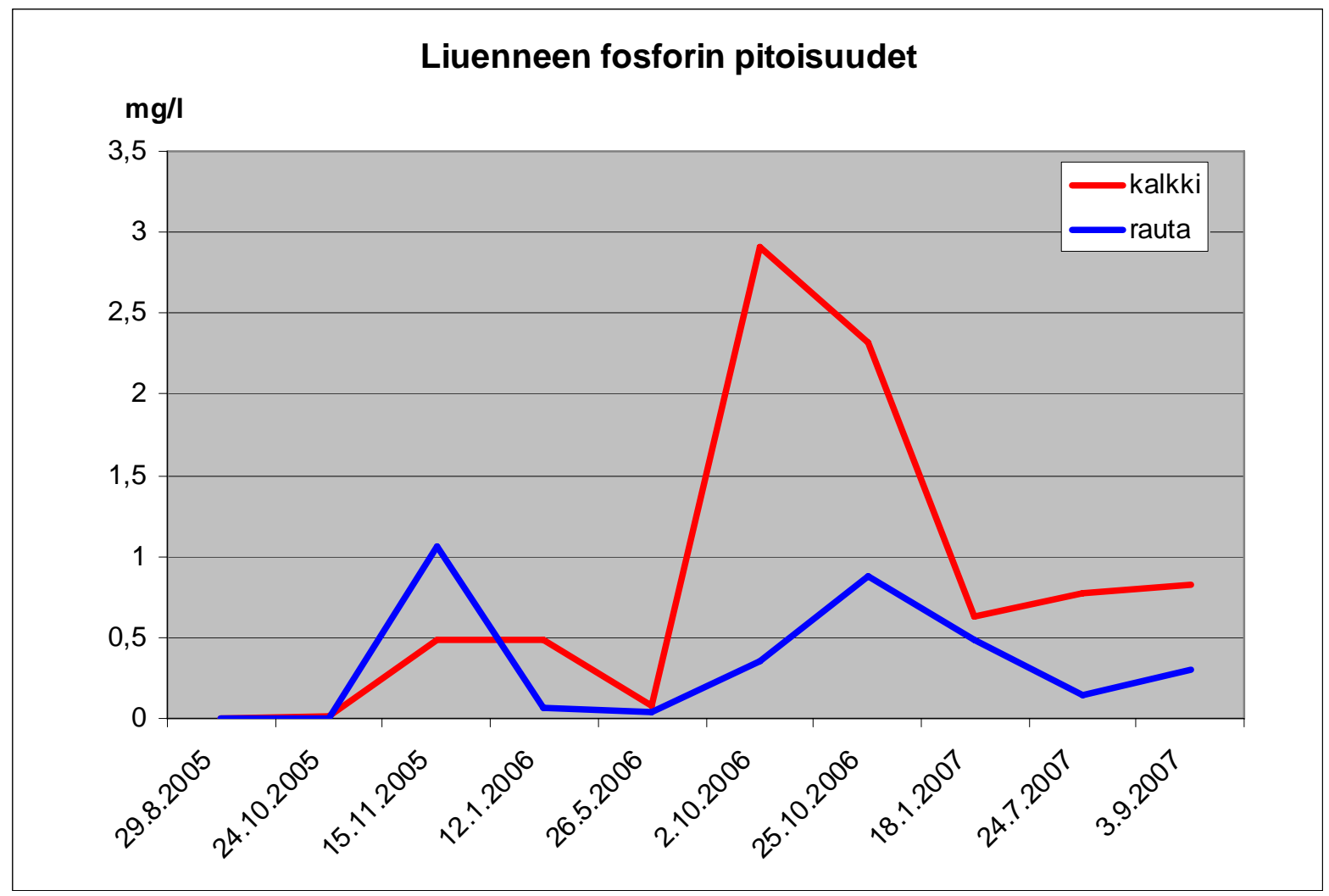

Kuva 5. Kuuman haketarhojen salaojavesien liuenneen fosforin pitoisuudet.

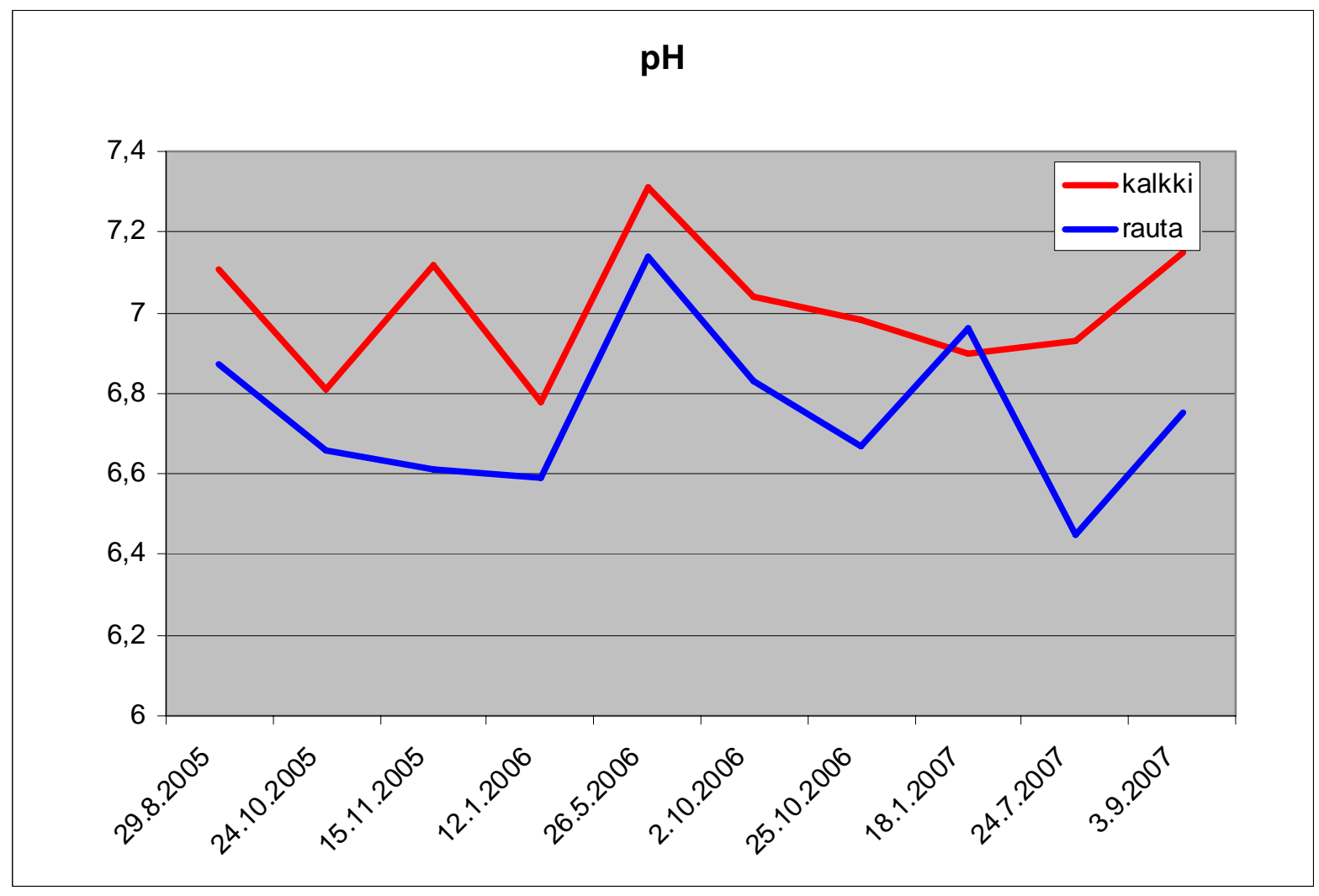

Kuva 6. Kuuman haketarhojen salaojavesien pH:t. 


\section{Johtopäätökset}

Tietyillä valuma-alueilla hevostaloudesta aiheutuva vesistöjen ravinnekuormitus voi olla huomattavan suuri. Valumavesien kemiallinen fosforin saostus Ferix-3:lla laskeutusaltaan yhteydessä osoittautui toimivaksi keinoksi vähentää hevostarhojen ravinnekuormitusta. Tässä käsittelyssä veden pH laskee yli yhden pH-yksikön. Tämä ei ole ongelma, koska käsitelty vesimäärä on pieni ja tarhavesien $\mathrm{pH}$ on yleensä yli seitsemän. Ferix-3:lla käsitellyn haketarhan salaojavesi oli rakennushienokalkilla käsiteltyyn verrattuna parempi. Kuitenkin havaittiin, että keväällä jäiseltä tarhapinnalta lähti huomattavia määriä vettä pintavaluntana ja salaojavalunta alkoi vasta paljon myöhemmin.

\section{Kirjallisuus}

Airaksinen S, Heiskanen M-L, Heinonen-Tanski H. 2007. Contamination of surface run-off water and soil in two horse paddocks. Bioresource Tech. :98:1762-1766

Närvänen, A., Jansson, H. 2007. Ferrisulfaatti saostaa ojavesistä liuenneet fosforit. Maaseudun Tiede 64, 2(22.10.2007): 13.

Närvänen, A., Jansson, H., Jansson, H. 2001. Saostus puhdistaa hevosten juoksutarhojen valumavedet. Koetoiminta ja käytäntö 58, 3(15.10.2001): 2

Närvänen, A., Jansson, H., Uusi-Kämppä, J., Jansson, H. \& Perälä, P. 2007. Phosphorus load from equine critical source areas and its reduction using ferric sulphate. Boreal Env. Res. (Revised manuscript)

Uusi-Kämppä, J., Heinonen-Tanski, H., Huuskonen, A., Jansson, H., Jansson, H., Kuisma, M., Nykänen, A., Närvänen, A. \& Puumala, M. 2008. Jaloittelu- ja ulkotarhoista aiheutuvan vesistökuormituksen vähentäminen vaikeaa. In: Maataloustieteen päivät 2008.

Uusi-Kämppä, J., Hyvärinen, M., Kuisma, M., Nykänen, A., Jansson, H., Jansson, H. \& Närvänen, A. 2007 a. Faecal microorganisms in runoff from cattle and horse farms; quantification and mitigation. In: Aland, A. (ed.). XIII International Congress in Animal Hygiene ISAH-2007, June 17-21, 2007, Tartu, Estonia. Animal Health, Animal Welfare and Biosecurity. Proceedings volume 2. p. 909-914.

Uusi-Kämppä, J., Närvänen, A., Jansson, H. \& Jansson, H. 2007b. Hevostarhojen fosforit ja mikrobit kuriin. Maaseudun tiede 2/2007 (22.10.2007). 